\title{
Sport: Instinct and Ancestry
}

\author{
Mark Brooke* \\ National University of Singapore, Singapore \\ Submission: April 11, 2018; Published: May 23, 2018 \\ *Corresponding author: Mark Brooke, Centre For English Language Communication, National University of Singapore, Singapore, \\ Email: elcmb@nus.edu.sg
}

Keywords: Ancestry; Instinct; Flight; Olympics; Social brain; Tribes; Societies; Civilising; Exemplification; Lacrosse; Mammals; Myriad relics; Spring; Citizens; History.

\section{Opinion}

This article explores the beginnings of sport and its development over time in the civilising process. It clearly started as a product of survival and fight or flight mechanisms. However, it is also representative of a desire to cooperate and helps to show the workings of the human social brain. Even in its early days, sport was viewed as a means to avoid war and massacre. Sport has thus played an essential role in the stabilisation of our societies and been a driving force in the Civilising Process [1].

Freud (1916-1917) pointed out that the quintessential primeval motivations of fight and flight response tend to dictate much of our actions. These responses are embedded deeply in the unconscious controlled by the hypothalamus of the brain which can initiate a succession of events in the autonomic nervous, endocrine and immune systems when required. In Sports in the Western World, Baker [2] posits that competition, as an integral element of the instinctive fight and flight response, is too an innate need, when he says from deep within, and from millennia past, comes the impulse for athletic competition. Indeed, The Darwinian mechanism of natural selection and the survival of the fittest is exemplification of this. Today in the Arapesh tribe of New Guinea, rivals, or ano'in, are those who have killed game or taken women from the tribal territory; both are fundamentally related to survival.

Sport has developed from instinctual drives and the struggle for survival. At least, the ubiquity of sport might be related to these needs as it provides a platform for them to be experienced. Interestingly, sport has been used to prevent large-scale murder in a number of societies. Dating as far back as ancient Olympia, dragon boating was first practised as a competitive race to end disputes between villages in Southern China. The ancient Olympics themselves occurred every four years and during the events, a sacred truce was held between the warring states. PokA-Tok is a ball game that the ancient Maya played in the Cancun and Riviera Maya areas. It is probable that the Aztecs also played a version of it because areas with the stone hoop on the wall can be found throughout Mexico. The Mayans used the sport to solve issues between fighting rivals (Figure 1).

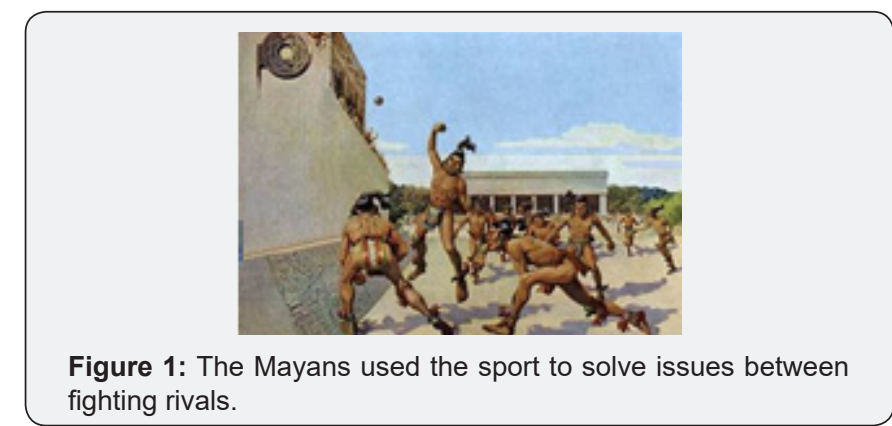

In the same way, Lacrosse was played by the American Indians as early as 1100CE. It was specifically attributed to the cultural tradition of the Iroquois. The game could last for several days and in part acted as a kind of symbolic warfare between rival tribes. Participants were viewed as warriors who brought honor to their tribe [3]. Even today, the Iroquois consider Lacrosse sacred. Onondaga faith keeper Oren Lyons states: "When you talk about the lifeblood of the six nations...the game is ingrained in our culture, and our systems, and our lives...there are two times of the year that stir the blood...In the fall for the hunt, and now (spring) for the Lacrosse" [4] (Figure 2).

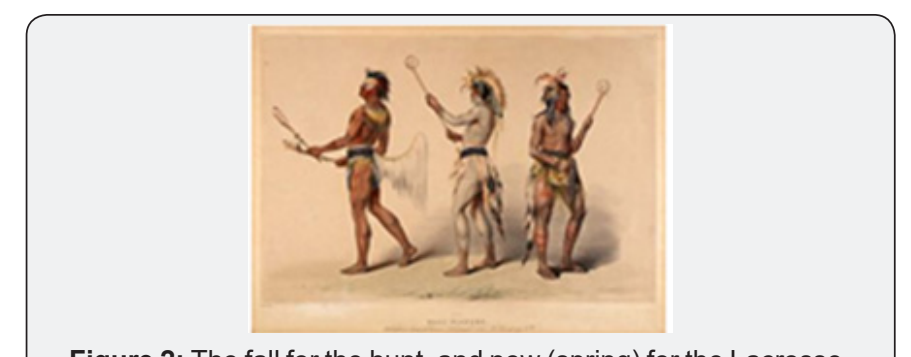

Figure 2: The fall for the hunt, and now (spring) for the Lacrosse.

In many ways, sport was a humane way to deal with these rivalry issues as whole armies were not involved. Annihilation of 
the opponent through war would seem most fitting for natural selection. This leads us to conclude that while humans may indeed have an innate competitive impulse, collaboration has also been essential throughout human history as a means for survival. Hence, sport can be linked to instinctual drives of fight and flight response and the struggle for survival but it can also be viewed as a form of cooperative endeavour. Primitive peoples are illustrated in cave paintings as groups collaborating to hunt game, using tools still pertaining to track and field, too large to be taken by an individual (Figure 3).

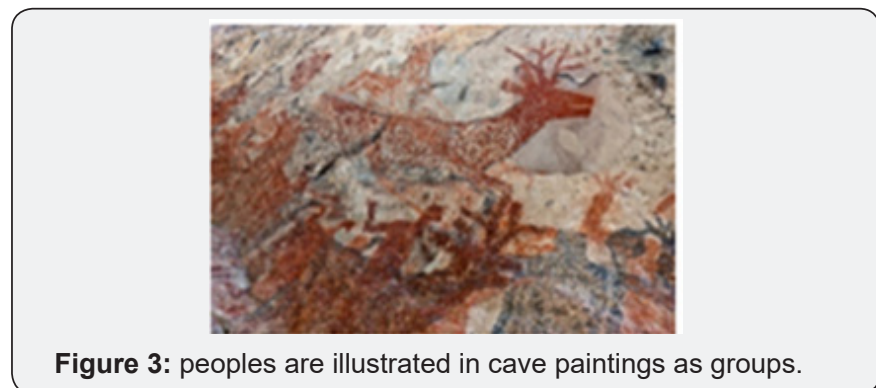

Dunbar's [5] "social brain hypothesis" demonstrates that mammals, and particularly humans, have always been social animals and this helps as evidence for the idea that cooperation is also innate. Elias has a similar theory; the consciousness of each individual has a social collective history, a process of development he calls "sociogenetic". For Dunbar, this social brain is in part evidenced by how humans are good at reading minds. Knowing a member of the tribe's intentions based on prior experience and observations was an essential element of the hunt and today is an essential part of sport too. It is crucial to be able to predict the actions of opponents and teammates. Success largely depends on understanding their mental states and intentions.

The ubiquity of sport throughout history can be seen to be an integral part of the civilizing process Elias [1]. Sport has become the medium for sanctioned display of quintessential primeval motivations in a relatively safe environment. It provides the same thrills of flight or fight as an athlete experiences the intensity of fear, pain, sadness and joy without destruction. It also appears to have had a great role in the formation of morality and the human conscience as well as the development of the social brain. Why else would it have been used to resolve rivalry issues to avoid mass murder and why else would being able to read someone's thoughts and predict their actions before they act, be so important a characteristic of sport?

Using Mead's [6] notion of the social object, sport and its myriad relics and conventions can be viewed as a collective phenomenon embodying shared meaning and directing specific ways of being. Teams still have totems to demonstrate that they are symbolic collective entities representing a unified identity (Figure 4).

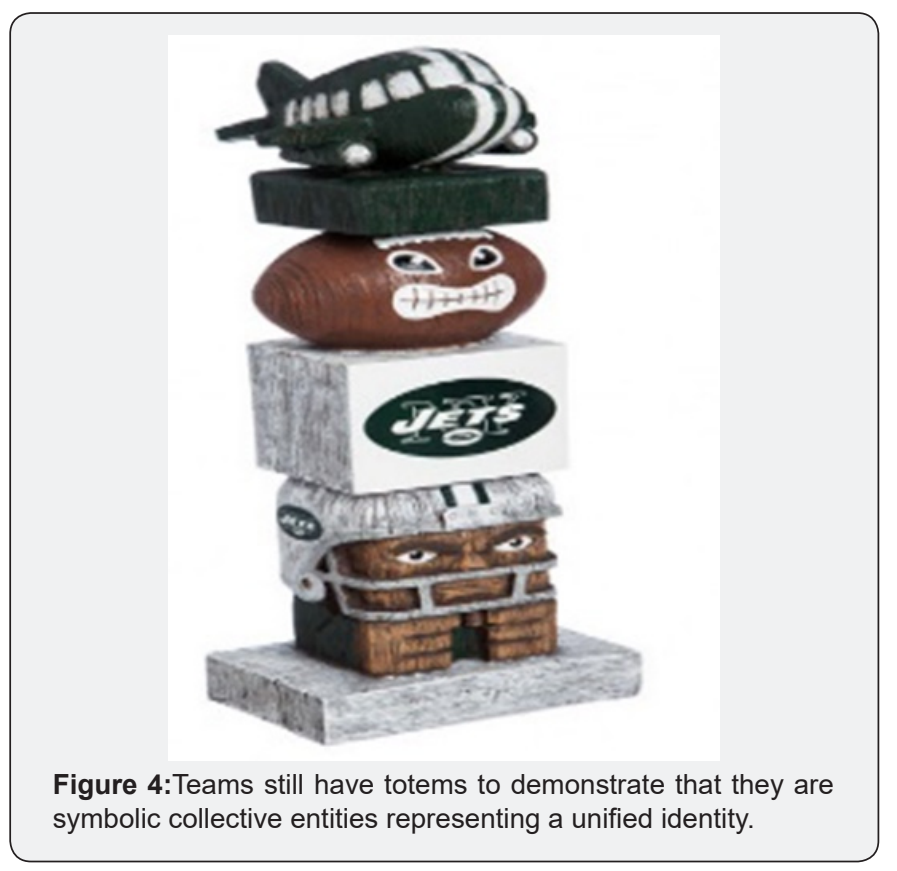

Throughout history, sport has been essential for human existence. Instincts have been experienced and morality developed through it. Today's sport may seem quite different to those games played in ancient times, but the same quintessential characteristics are present and part of our everyday rituals. As Norbert Elias points out in his work The Civilising Process, history has seen the development of "a chain of mutual dependence" between citizens as they strive to achieve their goals. The interdependence of human reality has increasingly led to more stability. As has been shown in this paper, sport has played an essential role in this stabilisation.

\section{References}

1. Elias N (2000) The Civilizing Process (edn), Blackwell Malden, USA.

2. Baker WJ (1988) Sports in the western world. University of Illinois Press. Urbana, USA.

3. Rock T (2002) More Than a Game. Lacrosse Magazine. Lacrosse, USA.

4. Engstrom D (2000) Exploring Northeast Native Americans: The Iroquois Seneca, Cayuga, Tuscarora, Onondaga, Oneida and Mohawk. Denver Public Schools, Colorado, USA.

5. Dunbar RI (1998) The social brain hypothesis. Brain 9(10): 178-190.

6. Mead GH (1925) The genesis of the self and social control. The International Journal of Ethics 35(3): 251-277. 
(C) Commons Attribution 4.0 License BY DOI: 10.19080/GJAA.2018.04.555633

\section{Your next submission with Juniper Publishers}

will reach you the below assets

- Quality Editorial service

- Swift Peer Review

- Reprints availability

- E-prints Service

- Manuscript Podcast for convenient understanding

- Global attainment for your research

- Manuscript accessibility in different formats

( Pdf, E-pub, Full Text, Audio)

- Unceasing customer service

Track the below URL for one-step submission https://juniperpublishers.com/online-submission.php 